\title{
L CAFÉ DE ESPAÑA (1886) DE VALENCIA, UN CAPRICHO ARQUITECTÓNICO INSPIRADO EN LA ALHAMBRA ${ }^{1}$
}

\author{
MÓNICA VÁZQUEZ ASTORGA
}

Universidad de Zaragoza mvazquez@unizar.es

\begin{abstract}
Resumen: En este trabajo se reconstruye y analiza la historia del desaparecido café de España de Valencia, que fue inaugurado el primero de mayo de 1886. En su instalación y decoración intervinieron empresas, artistas y artesanos valencianos. Este espacio para la práctica de la sociabilidad pública fue único en su categoría y sobresalió por su suntuoso ambiente. De hecho, fue considerado como uno de los mejores de Europa y, según Azorín -uno de sus tertulianos-, "no lo habría tampoco en el mismo París". Se convirtió en un lugar emblemático de la vida social y cultural de esta ciudad.
\end{abstract}

Palabras clave: Carmelo Lacal Sorlí / Antonio Cortina Farinós / café de España / Valencia / espacios de sociabilidad pública/ cafés históricos.

\section{THE CAFÉ DE ESPAÑA (1886) IN VALENCIA, AN ARCHITECTURAL CAPRICE INSPIRED BY LA ALHAMBRA}

Abstract: This work reconstructs and analyses the history of the now-defunct café de España in Valencia, which opened on 1 May 1886. It was set up and decorated by companies, artists and artisans from Valencia. This space for public sociability was unique in its type and shone for its luxurious atmosphere. In fact, it was considered one of the best in Europe and, in the words of Azorin, one of its patrons, "it has no equal even in Paris". The café became an emblematic symbol of the city's social and cultural life.

Key words: Carmelo Lacal Sorlí / Antonio Cortina Farinós / café de España / Valencia / spaces for public sociability / historic cafés.

No se puede esperar a que se haya borrado la última huella para empezar a buscarla. ${ }^{2}$

\section{Introducción}

Hacia mediados del siglo XIX y, especialmente tras la instauración de la Restauración borbónica en 1874 , se valoró en arquitectura una imagen pintoresquista y exótica con la adopción de una tendencia orientalista que tuvo como principal referente el monumento de la Alhambra de Granada, ${ }^{3}$ cuya restauración favoreció la imitación de su repertorio ornamental. ${ }^{4}$ Como indica Tonia Raquejo,

\footnotetext{
* Fecha de recepción: 15 de octubre de 2019 / Fecha de aceptación: 20 de septiembre de 2020.

1 Esta investigación se ha desarrollado en el marco del Proyecto Distritos culturales de museos, galerías, establecimientos y paisajes urbanos patrimoniales (código HAR2018-094351-B-C41), financiado por la Secretaria de Estado de I+D+i del Ministerio de Ciencia, Innovación y Universidades.

2 Cita de Valeriano Bécquer (1833-1870) tomada del texto de RUBIO JIMÉNEZ, Jesús. Los Bécquer en Veruela. Un viaje artísticoliterario. Zaragoza: Ibercaja, 1990, p. 51.

3 A este respecto, es interesante mencionar que los viajeros británicos fueron los pioneros en divulgar por Europa la imagen romántica de España y en fijar una serie de lugares para el recuerdo como la Alhambra de Granada, la Giralda de Sevilla o la mezquita de Córdoba. Como señala Luis Sazatornil, fue a partir de 1830 cuando, casi simultáneamente, viajaron por nuestra geografía cuatro de los principales referentes británicos en la construcción de la imagen romántica del país: Richard Ford, David Roberts, John Frederick Lewis y George Vivian. Su llegada coincidió con la del pintor Wilhelm Gail, considerado uno de los precursores alemanes del viaje a España, y con las de los franceses Joseph-Philibert Girault de Prangey o Adrien Dauzats. SAZATORNIL RUIZ, Luis, 2019, p. 67.

${ }^{4}$ Esta imagen romántica fue potenciada por los primeros restauradores de la Alhambra, como fue el caso de Rafael Contreras,
} 
este palacio se convirtió en el símbolo de la cultura musulmana por lo que resultó, debido a su origen medieval y oriental, doblemente romántico. ${ }^{5}$ No fue el único de los revivals desarrollados dentro del historicismo que irrumpió en aquel entonces pero fue el estilo más representativo en las exposiciones universales de esa centuria por las connotaciones de evasión y exotismo que comportaba. ${ }^{6}$ Además, nuestro territorio era un terreno abonado donde fácilmente era presumible que surgiera un orientalismo arquitectónico.

Este ambiente de gusto oriental, que estaba asociado con la idea de lujo y poder, fue apreciado para las villas o palacetes señoriales, así como para los edificios de recreo y esparcimiento (teatros, cafés, circos, etc.), por lo que tenía también de festivo. Un testimonio notable fue el desaparecido café de España de Valencia, cuyo salón árabe y su magnífica decoración evidencian el importante alcance que tuvo la corriente orientalista, que entraría en decadencia con el cambio de siglo. Este café fue fundado en 1886 cuando este tipo de establecimientos para la práctica de la sociabilidad públi$\mathrm{ca}^{7}$ había conseguido su mayor apogeo como lugares confortables y lujosos, ${ }^{8}$ en la línea de los parisinos que se habían convertido en modelo para todos los locales europeos. ${ }^{9}$

Como bien señala Jesús Cruz, los cafés fueron, junto con los teatros, casinos, ateneos, sociedades recreativas o paseos, los espacios de sociabilidad más destacados para la sociedad burguesa del siglo $\mathrm{XIX}_{i}{ }^{10}$ una sociedad de buen tono que dictaba las normas de comportamiento a través de la moda y el refinamiento. Su función de puntos de encuentro (don- de, además de tomar café -u otros productos como licores, sorbetes o helados-, se podía leer la prensa, conversar, intercambiar opiniones, fomentar las relaciones sociales o difundir nuevas formas de pensamiento) contribuyó a la formación de un importante tejido sociocultural urbano. ${ }^{11}$

Para abordar el estudio de este café valenciano, se analiza, en primer lugar, el panorama arquitectónico correspondiente al reinado de Isabel II y al último tercio del siglo XIX, con el objetivo de comprender y valorar sus instalaciones y los trabajos de decoración de sus interiores en relación con otros establecimientos de aquella época; y, en segundo lugar, se reconstruye el devenir de este lugar de congregación social desde su fundación hasta su desaparición, determinando su repercusión como espacio de sociabilidad pública.

\section{En busca de una "arquitectura nacional"}

A partir de mediados del siglo XIX se advierte en nuestro panorama arquitectónico la influencia de las visiones románticas europeas con su peculiar matiz nacionalista fundamentado en la búsqueda de arquitecturas pretéritas singulares o gloriosas. En opinión de Francisco Calvo Serraller, la exaltación de los estilos medievales, así como de un amplio espectro de "resurrecciones clásicas" de toda índole (neogriego, etc.), se engloba en el proceso que se conoce como historicismo, de raíces dieciochescas y con una proyección histórica que abarca, cuanto menos, por completo el siglo XIX. ${ }^{12}$

La exaltación de estilos pasados fue gestándose en los años cuarenta y cincuenta del siglo XIX -durante la etapa isabelina, cuyo gobierno liberal favoreció la revitalización de las artes-, aunque su verdadera

que fue nombrado restaurador adornista de este monumento en 1847. Sobre la intervención de este arquitecto, véase SERRANO ESPINOSA, Francisco, 2014.

5 RAQUEJO, Tonia, 1989, p. 16.

${ }^{6}$ Su máximo grado de representatividad, como señala M. ${ }^{a}$ José Bueno Fidel, se alcanzó en los pabellones oficiales de las exposiciones universales, tal como se advierte en la fachada del pabellón español para la Exposición Universal de París de 1878 (diseñado por el arquitecto Agustín Ortiz de Villajos), en la que junto a referencias alhambristas se encuentran otras a la mezquita cordobesa. BUENO FIDEL, M. ${ }^{a}$ José, 1987, p. 34; y La Ilustración española y americana, 22-VI-1878, “Exposición Universal de París", p. 406-408. Asimismo, sobre el tema de la imagen de Andalucía y la difusión de modelos arquitectónicos basados en el legado oriental en los certámenes universales del siglo XIX se recomienda la consulta, entre otras publicaciones, de MÉNDEZ RODRÍGUEZ, Luis, 2008, p. 101-123.

7 Estos espacios han sido estudiados a través del concepto de sociabilidad definido por el hispanista Jean-Louis Guereña como la aptitud de los hombres para relacionarse en colectivos más o menos estables, más o menos numerosos, y a las formas, ámbitos y manifestaciones de vida colectiva que se estructuran con este objetivo. GUEREÑA, Jean-Louis, 2003, p. 413.

8 La Edad de Oro de nuestros cafés, como indica Antonio Bonet, coincide con los años de la Restauración y de la regencia de María Cristina de Habsburgo, durante el último tercio del siglo XIX y los primeros años del siglo XX. BONET CORREA, Antonio, 2012, p. 38.

9 VÁZQUEZ ASTORGA, Mónica, 2015, p. 23-37.

10 CRUZ VALENCIANO, Jesús, 2014, p. 50.

11 RIBAGORDA, Álvaro, 2009, p. 41.

12 CALVO SERRALLER, Francisco, 1995, p. 165-166. 
reivindicación no se produjo hasta el último tercio de esa centuria. En un principio, el acercamiento a la arquitectura historicista estuvo más influenciado por un deseo de motivos exóticos y pintorescos que por la búsqueda de "raíces nacionales". ${ }^{13}$

Este interés justifica que el estilo árabe o neoárabe -como era denominado en la época- fuera uno de los más demandados por las clases acomodadas -porque sugería la evocación de tierras lejanas, ensueños y placeres- y utilizado en palacios y casas de recreo, villas y todas aquellas construcciones que tuvieran relación con el ocio y la diversión (casinos, casas de baños, salas de baile, etc.), así como con la jardinería (mercados de flores, quioscos, etc.). ${ }^{14}$ Como gran parte de esas imitaciones y referencias a la arquitectura musulmana estaban fundamentadas en la Alhambra de Granada, Pedro Navascués acuñó el término alhambrismo para denominar este revival que tiene en ella su origen, aunque en la mayoría de las ocasiones se estuviese lejos de un valor arqueológico. ${ }^{15}$ Este fenómeno fue también aplicado a la literatura, a la música y a las artes decorativas.

Asimismo, Pedro Navascués señala que la guerra fue un factor decisivo en la difusión del gusto oriental. De hecho, se refiere a la "guerra de Oriente", que tuvo su momento de apogeo en 1877 y "llevó a los periódicos y sobre todo a las revistas ilustradas escenas de costumbres, muebles, vestuario y vistas de distintas ciudades orientales, en especial de Constantinopla". Todo esto sirvió de base para elaborar en Occidente formas orientales que, en definitiva, no hacían sino completar el movimiento iniciado en el siglo XVIII hacia las civilizaciones no europeas. ${ }^{16}$

En opinión de Oriol Bohigas, que se centra en Cataluña, fue decisiva para la propagación de esta moda la batalla de Tetuán que ganó el general Prim en 1860, la cual provocó una "euforia nacional, arranque entusiasta y, a la vez, una evocación plástica de los temas orientales, en concordancia con la ideología romántica". ${ }^{17}$

A este impulso se sumaron, entre otras acciones, la prolífica bibliografía histórico-artística que apareció en Europa referida al mundo musulmán ${ }^{18} \mathrm{y}$ los discursos leídos en la Real Academia de Bellas Artes de San Fernando. A este respecto, cabe aludir a los pronunciados en la recepción pública del historiador granadino Juan Facundo Riaño sobre "Los orígenes de la arquitectura arábiga, su transición en los siglos XI y XII y su florecimiento inmediato" (1880), ${ }^{19}$ y del arquitecto navarro Adolfo Fernández Casanova sobre el "Arte mauritano" (1892). ${ }^{20}$

El primer acercamiento al pasado islámico se constata en el gabinete árabe o de fumar del Palacio Real de Aranjuez, concebido para la reina Isabel II por el arquitecto granadino Rafael Contreras Muñoz en 1848; y en el salón del Palacio de la finca de Vista Alegre en Carabanchel Bajo (Madrid) ${ }^{21}$ (Fig. 1), realizado a finales de los años cincuenta con el fin de recordar la Sala de la Barca de la Alhambra, con todo el repertorio formal y polícro-

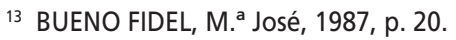

14 BUENO FIDEL, M. ${ }^{a}$ José, 1987, p. 25.

15 NAVASCUÉS PALACIO, Pedro, 1973, p. 93 y 139.

16 NAVASCUÉS PALACIO, Pedro, 1973, p. 263.

17 BOHIGAS, Oriol, 1968, p. 243.

${ }^{18}$ A este respecto, pueden citarse, entre otras, las siguientes publicaciones que revalorizaron esta cultura: DOZY, Reinhart. Histoire des Mussulmans d'Espagne, jusqu'à la conquéte de l'Andalousie par les Almoravides. Leyde: E. J. Brill, 1861; ALMAGRO CÁRDENAS, Antonio. Museo granadino de antigüedades árabes: colección de estudios arqueológicos sobre los monumentos árabes de Granada que hoy se conservan en poder de particulares y datos sobre otros que ya han desaparecido. Granada: Imprenta de La Lealtad, 1886; CONTRERAS, Rafael. Estudio descriptivo de los monumentos árabes de Granada, Sevilla y Córdoba o sea La Alhambra, el Alcázar y la Gran Mezquita de Occidente. Madrid: Imprenta y Litografía de A. Rodero, 1878.

19 RIAÑO, Juan Facundo. Los orígenes de la arquitectura arábiga, su transición en los siglos XI y XIl y su florecimiento inmediato. Madrid: Imprenta y Estereotipia de Aribau y C. , 1880. Discurso leído el 16 de mayo de 1880 en la Real Academia de Bellas Artes San Fernando.

20 FERNÁNDEZ CASANOVA, Adolfo. El arte mauritano. Madrid: Imprenta y Litografía de los Huérfanos, 1892. Discurso de ingreso pronunciado el 12 de junio de 1892 en la Real Academia de Bellas Artes de San Fernando.

${ }^{21}$ La regia posesión de Vista Alegre en Carabanchel pasó a pertenecer en 1829 a la reina María Cristina de Habsburgo y a partir de 1846 a sus hijas Isabel II y María Luisa Fernanda, hasta que en 1859 fue adquirida por José de Salamanca Mayol, marqués de Salamanca. Su nuevo dueño aumentó la propiedad con la compra de terrenos en el camino de Madrid y encargó terminar las obras del palacio nuevo al arquitecto Narciso Pascual y Colomer. La Ilustración española y americana, 30-I-1883, p. 68-69; PRIEGO, Carmen (ed.), 2009, p. 80-81. Sobre la posesión real de Vista Alegre se recomienda la consulta, entre otras publicaciones, de ARIZA MUÑOZ, Carmen, 1985, p. 37-44; ARIZA MUÑOZ, Carmen, 1986, p. 519-537; CRUZ VALENCIANO, Jesús, 2015, p. 37-54. 


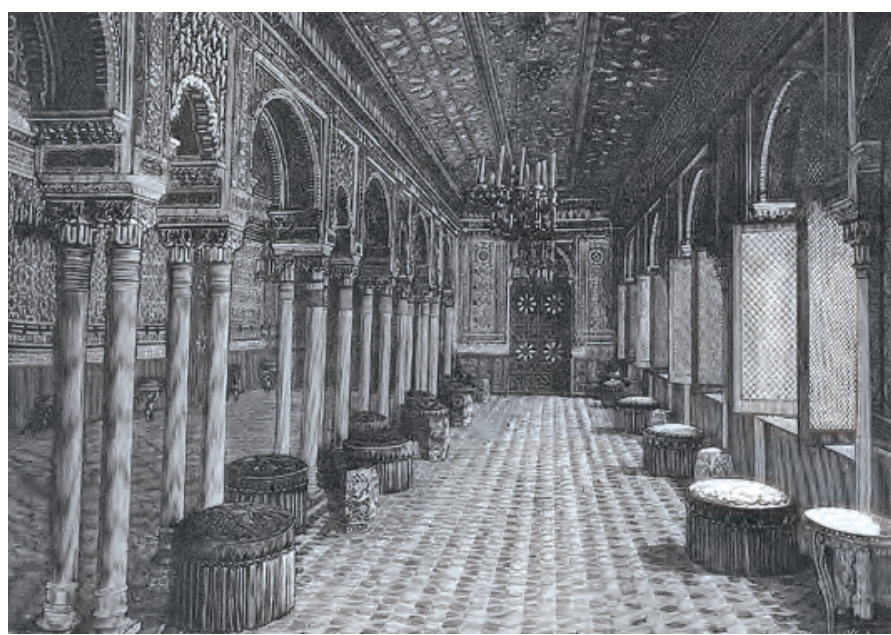

Fig. 1. Salón árabe del palacio del marqués de Salamanca en la Quinta de Vista Alegre, Madrid, 1883 (La Ilustración española y americana, 30-I-1883). Biblioteca de la Diputación Provincial de Zaragoza.

mo granadino. 22 Fue, por tanto, una moda iniciada por la realeza, al igual que ya lo habían hecho otras monarquías, como la inglesa. ${ }^{23}$

Este gusto que estaba en boga pasó a ser imitado por la aristocracia y la burguesía, cuyos ejemplos más notorios son el Palacio de José Xifré Downing (paseo del Prado, construido entre 1862 y 1865) y el Palacio de Anglada (paseo de la Castellana, erigido hacia 1876 y en cuyo interior contaba con un patio que remedaba el de los Leones de la Alhambra), ${ }^{24}$ ambos demolidos. El primero mencionado, en opinión de Pedro Navascués, era posiblemente "el más característico pastiche neoárabe que se ha hecho en nuestro país y un modelo acabadísimo del capricho arquitectónico burgués". ${ }^{25}$ Esta moda se extendió en otras ciudades como en Barcelona, ${ }^{26}$ tal como queda de manifiesto, por ejemplo, en el salón de fumar de la casa Vicens (calle de las Carolines, 1883-1888), obra del arquitecto Antonio Gaudí.

También, los cafés, al igual que otros espacios para la práctica de la sociabilidad pública (teatros, casinos, pasajes comerciales, etc.), acogieron con complacencia esa estética no solo porque los países árabes fueron el lugar de origen de la bebida que les daba nombre sino también para favorecer que su distinguida clientela pudiera evadirse y deleitarse mientras tomaba una aromática taza de café. Muchos fueron los cafés europeos de estos años que bien se denominaron Oriental / de Oriente o bien rememoraron con su decoración el exotismo de esa cultura, como fue el caso del madrileño café Oriental (Puerta del Sol, núms. 11 y 12, con esquina a las calles de Tetuán y Preciados), ${ }^{27}$ cuya apertura se verificó el 19 de octubre de 1861 y comprendía un amplio y lujoso salón; 28 del café Oriental de Zaragoza que se inauguró el 20 de julio de 1900 en la planta baja del edificio situado en la calle del Coso, núm. $39,{ }^{29}$ haciendo esquina con la calle de los Mártires (Fig. 2); ${ }^{30}$ o del Grand Café Orient de Praga (Ovocný trh 19, 1911-1912). ${ }^{31}$

22 Pedro Navascués señala que se desconoce si este salón fue encargado por la reina Isabel II, en la línea del que ya tenía en Aranjuez, o si se debe a una iniciativa del marqués de Salamanca. De cualquier forma su autor podría ser el arquitecto Rafael Contreras, quien entonces estaba trabajando en la restauración de la Alhambra de Granada. NAVASCUÉS PALACIO, Pedro, 1983, p. 87-88.

${ }^{23}$ La mayoría de estos salones fueron construidos en palacetes y casas particulares, por lo que, en gran parte, han desaparecido. NAVASCUÉS PALACIO, Pedro, 1983, p. 94.

24 Este palacio fue encargado por el banquero Juan Anglada y Ruiz al arquitecto Emilio Rodríguez Ayuso. La Ilustración española y americana, 15-IX-1880, "Pintura decorativa. El palacio del señor Anglada", p. 155; NAVASCUÉS PALACIO, Pedro, 1983, p. 35.

${ }^{25}$ El palacio Xifré fue construido según el proyecto del arquitecto francés Boeswildbald. Su propietario, José Xifré Downing (hijo de un rico y emprendedor indiano catalán, Xifré Casas) costeó a varios especialistas franceses una expedición a Oriente con el objetivo de que durante un año reunieran antigüedades árabes (tapices, muebles, etc.) con destino a este palacio. NAVASCUÉS PALACIO, Pedro, 1983, p. 28-29.

26 PASCUAL SANPONS, Oriol, 2017 analiza la arquitectura de inspiración oriental que se desarrolló en Barcelona, entre 1859 y 1914.

27 Archivo de Villa de Madrid [A.V.M.], Secretaría, Sección 11, Caja 18, expediente núm. 96: "Solicitud de licencia para café en Puerta del Sol, núms. 11-12", 1897.

28 Diario oficial de avisos de Madrid, 6-X-1861, "Variedades", p. 4; y Diario oficial de avisos de Madrid, 12-X-1861, "Variedades", p. 4.

29 FORTÚN SOFÍ, Ricardo (dir.), 1901, p. 369.

30 Archivo Municipal de Zaragoza [A.M.Z.], Sección de Policía Urbana, Licencias de obras, Caja 577, expediente núm. 642: “D. Fructuoso Obón pidiendo permiso para abrir un hueco para ventanas dentro de un rehundido de puerta en la fachada de la casa $n^{\circ} 39$ de la calle del Coso por la de los Mártires, construir una portada en el cuerpo bajo de ambas fachadas con puertas de acero ondulado", 1900. Para este establecimiento, su propietario (Fructuoso Obón) reformó la fachada y renovó el decorado 
No obstante, entre todos ellos se distinguió el café de España de Valencia por su espléndida ornamentación y la magnificencia de sus instalaciones y servicios, tal y como recoge el periodista burgalés Eusebio Martínez de Velasco:

Presenta un salón decorado en estilo árabe florido, según el modelo de la Alhambra, con gran riqueza de alicatados, azulejos, dibujos y arabescos de oro y vivos colores en sus ventanas pareadas, arcos, frisos, ménsulas, y en las cuatro hermosas lámparas que pendían del techo. ${ }^{32}$

El exotismo del neoárabe fue sustituido por el neomudéjar, puesto que para finales del siglo XIX el primero citado era considerado "excesivamente oriental y sensual", que se afianzó como el estilo por excelencia. ${ }^{33}$

\section{El café de España, más que un café}

El café de España estaba instalado en un edificio situado en la céntrica y populosa Bajada de San Francisco, núms. 7-9, esquina con la calle de Moratín, núm. 2 (hoy plaza del Ayuntamiento esquina con la calle de las Barcas) (Fig. 3), que fue construido por el maestro de obras Carmelo Lacal Sorlí (Carlet,?-Valencia, 1897). ${ }^{34}$ Su propietario era el conocido empresario aragonés Felipe Narbón, ${ }^{35}$ quien aprovechó el período de bienestar económico registrado entonces en la ciudad de Valencia.

La fachada principal de este inmueble fue resuelta dentro de un estilo historicista (con reminiscencias renacentistas), conforme a los criterios estéticos vigentes, y policromada (Fig. 4). ${ }^{36}$ Destacaba su claridad compositiva, puesto que se dividía en tres franjas verticales y el eje vertical de simetría se co-

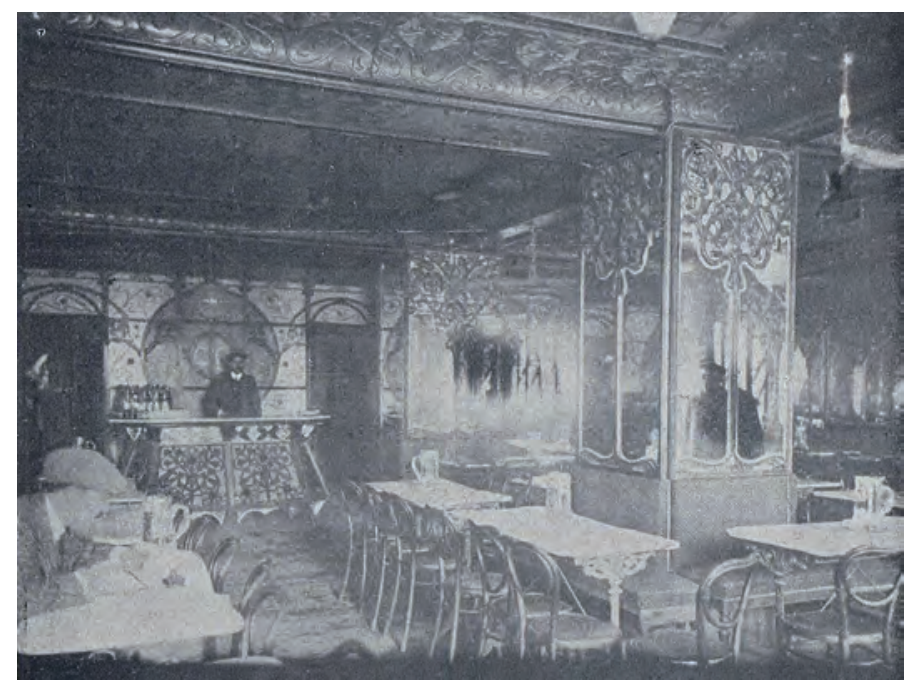

Fig. 2. Aspecto del interior del café Oriental de Zaragoza, 1908 (Guías Arco. Guía práctica de Zaragoza y su provincia. Madrid: Establecimiento Tipográfico de Antonio Marzo, 1908). Colección privada.

ronaba con una moldura a modo de frontón. Presentaba planta baja diáfana (con tres amplios huecos con el refuerzo de pilastras corintias) y dos en alzada con tres vanos rematados por arcos de medio punto, que en el piso principal se hallaban flanqueados por pilastras de capitel corintio para enfatizar su importancia. Por tanto, se empleó un esquema compositivo de base clasicista en el que la planta baja actuaba como cuerpo de base y se recurrió a pilastras de resabio clásico que conferían

interior (que evocaba la delicadeza y suntuosidad del mundo islámico). Esta decoración fue realizada conforme al proyecto de dos artistas aragoneses asentados en Barcelona: Valero Tiestos e hijo. Las obras fueron acometidas por el carpintero José Gracia, el escultor adornista Ricardo Bayod y los pintores Emilio Gil y Juan Bayod. La cristalería se debió a los talleres La Veneciana. Heraldo de Aragón, 21-VII-1900, "Noticias", p. 2.

31 Este café fue obra del arquitecto checo Josef Gočár. BONET CORREA, Antonio, 2012, p. 163.

32 MARTÍNEZ DE VELASCO, Eusebio, p. 171.

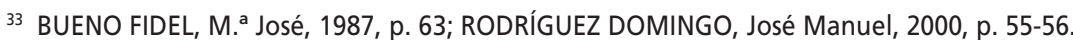

${ }^{34}$ Carmelo Lacal Sorlí fue maestro de obras por la Academia de Bellas Artes de San Carlos de Valencia y artista decorador. Se registran obras suyas en esta ciudad desde 1881 y hasta la fecha de su fallecimiento en 1897. BENITO GOERLICH, Daniel, 1992, p. 423; GIRONÉS SARRIÓ, Ignasi (coord.), 2013, p. 48. En su trayectoria profesional destaca el hecho de haber obtenido la concesión para realizar el proyecto y ejecución del primer tranvía a vapor entre Alberic y Valencia el 8 de diciembre de 1892. Revista ilustrada de vías férreas, 13-I-1893, "Noticias generales", p. 8.

35 Felipe Narbón y Graso falleció el 12 de noviembre de 1888. El Día, 12-XI-1888, "Noticias varias", p. 3. El historiador valenciano Manuel González Martí nos aporta los siguientes datos sobre Felipe Narbón: "fue un millonario baturro, que desde la infancia vivía en Valencia y ya maduro, en 1885, había identificado su claro entendimiento con los tantos problemas urbanísticos que de continuo presencia en Valencia [...]. Uno de estos, la falta de un hotel, de gran dignidad, para alojar a las personalidades de elevada categoría, que de continuo visitan Valencia; completado el edificio con la instalación en él, de un café. De amplia sala, donde se puedan reunir algunos centenares de concurrentes". GONZÁLEZ MARTí, Manuel, 1971, p. 167.

36 Arxiu Històric Municipal de València [A.H.M.V.], Sección de Policía Urbana, Licencias de obras, Caja 154, expediente núm. 2: "Edificio de la calle de la Bajada de San Francisco", 1885. 


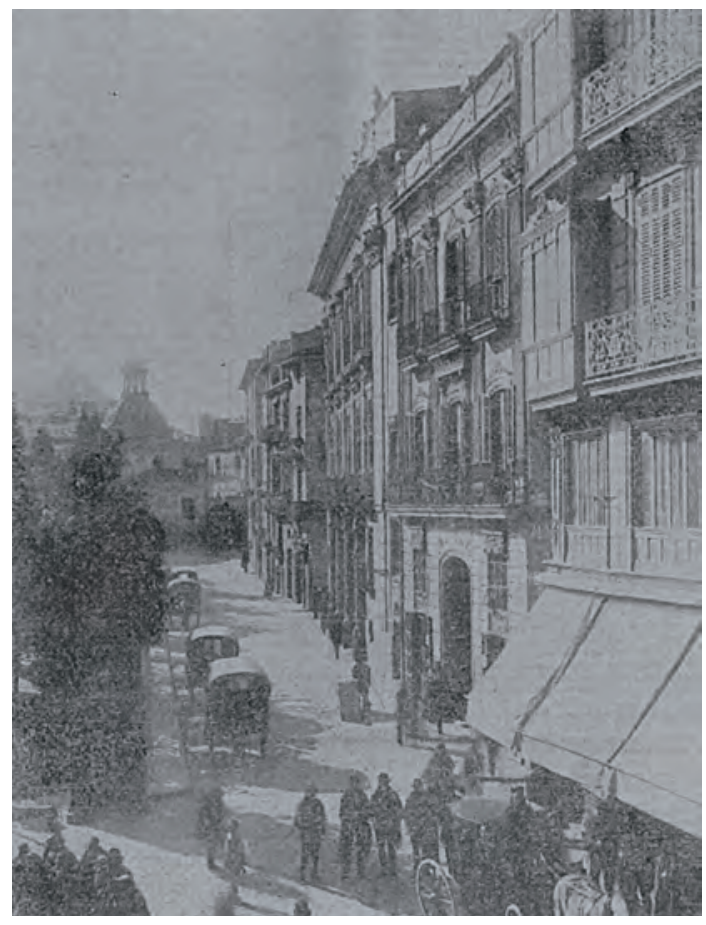

Fig. 3. Vista parcial de la plaza de San Francisco de Valencia, con el convento de San Francisco al fondo, finales del siglo XIX. Las Provincias. Diario de Valencia, 27-XII-1928.

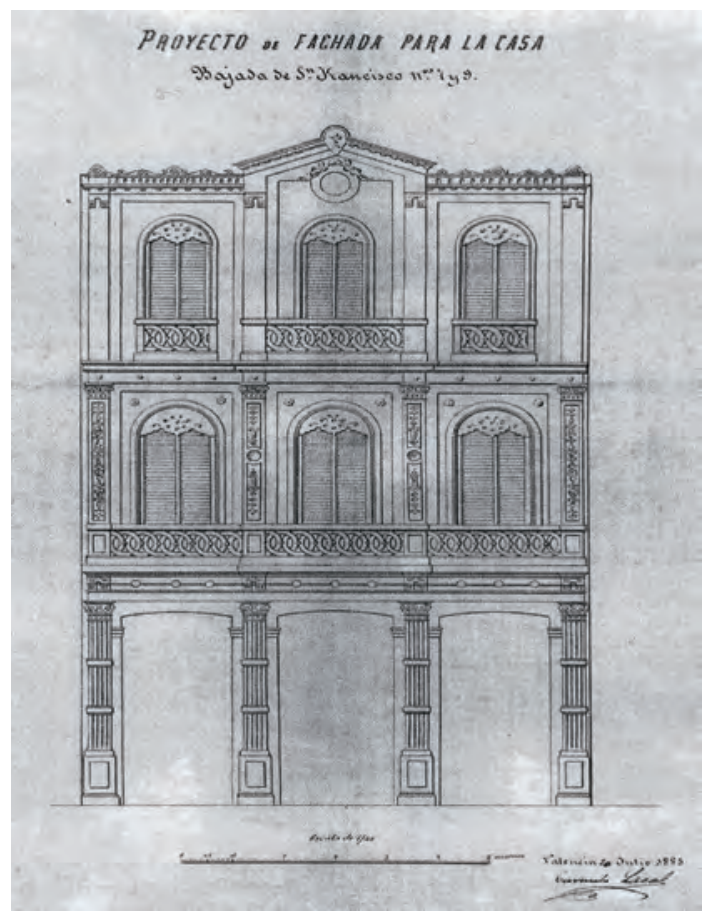

Fig. 4. Alzado de la fachada del edificio a construir en la Bajada de San Francisco, núms. 7-9, donde se ubicó el café de España, julio de 1885. Arxiu Històric Municipal de València. un marcado ritmo vertical al conjunto. La planta baja fue destinada a café y las restantes a hotelfonda, ${ }^{37}$ con el título de Fonda y café de España.

En la Bajada de San Francisco, en su número 19, también estaba emplazado, desde 1858, el café Suizo por la sociedad Francisco Matossi, Bernardo Fanconi y compañía. ${ }^{38}$ Estos empresarios tenían con el mismo nombre otros muy acreditados en ciudades como Bilbao (donde se abrió el primero de los cafés Suizos, en 1814), ${ }^{39}$ Madrid $^{40}$ Zaragoza, $^{41}$ Barcelona ${ }^{42}$ o Haro. ${ }^{43}$ Este prestigioso establecimiento fue reformado en el otoño de 1886 para adecuarlo a los gustos de la clientela y a las modernas necesidades de la época, abriendo nuevamente sus puertas la no-

37 La fonda se abrió en 1887 y tenía entrada desde la Bajada de San Francisco. En la planta primera comprendía amplias y elegantes habitaciones, un salón de descanso y lectura, un comedor y un restaurant (con capacidad para veintiocho mesas), entre otras dependencias. La siguiente planta acogía habitaciones, igualmente dotadas de buena iluminación y de inmejorables condiciones higiénicas. Las Provincias. Diario de Valencia, 2-VI-1887, "La nueva fonda de España", p. 2; MARTínEZ DE VELASCO, Eusebio, 1889, p. 171.

${ }^{38}$ El Valenciano, 14-IV-1858, "Valencia 14 de abril", p. 1.

${ }^{39}$ Este establecimiento ocupó el local de un antiguo café fundado en 1811 en la calle del Correo. BACIGALUPE, Carlos, 1995, p. 51-69.

40 Este café (calle de Alcalá, esquina con la Ancha de Peligros) fue inaugurado el 3 de junio de 1845. VÁZQUEZ ASTORGA, Mónica, 2019, p. 96.

${ }^{41}$ Este café se ubicó temporalmente en 1847 en el local del antiguo café de las Delicias y, en 1856, se trasladó a la planta baja de la casa situada en el paseo de la Independencia, núm. 2, esquina con la plaza de la Constitución, núm. 3. VÁZQUEZ ASTORGA, Mónica, 2015, p. 47-50.

42 El café Suizo de Barcelona se instaló en un inmueble de la plaza Real, núm. 17, en noviembre de 1857. VILLAR, Paco, 2013, p. 23 y 261-268.

${ }^{43}$ El café Suizo de Haro se halla emplazado en la planta baja de un edificio sito en la plaza de la Paz, que fue inaugurado como hotel en 1865. Tras su clausura, este café se conservó, aunque el 13 de febrero de 2017 cerró temporalmente sus puertas para abrirse completamente renovado el 3 de diciembre de 2018. VÁZQUEZ ASTORGA, Mónica, 2014, p. 219-220. 
che del 1 de diciembre de ese año, bajo la dirección de Federico Serrano. ${ }^{44}$ Por tanto, los cafés más concurridos de la urbe -al igual que los restaurantes, cervecerías, fondas y hoteles más refinados- se encontraban en esta zona y en sus inmediaciones.

El café de España fue inaugurado el 1 de mayo de 1886 y fue un verdadero acontecimiento para la ciudad. ${ }^{45}$ Para dar mayor esplendor al acto se amenizó con un septeto dirigido por el maestro Plasencia. Fue dotado con todos los avances y comodidades de la época. En julio de 1888 se instaló el alumbrado eléctrico -que sustituyó a la luz de gas- ${ }^{46}$ bajo la gestión de Llopis y compañía.

La planta baja daba acceso al café mediante un amplio vestíbulo, con pavimento de mármol y rico artesonado, que conducía a un majestuoso salón de planta rectangular (de 18 metros de largo, 7 de ancho y 6 de alto) que estaba decorado en "estilo árabe florido, según el modelo de la Alhambra de Granada" (Fig. 5). ${ }^{47}$ Presentaba elementos propios de la arquitectura musulmana (aunque sin ceñirse rigurosamente al palacio nazarí) con arcos angrelados encuadrados en su alfiz, que se sustentaban en esbeltas columnas de capitel cúbico y estilizado fuste, y que estaban engalanados de ataurique. Un friso en relieve recorría la sala e incluía inscripciones en caracteres arábigos que decían "Al Andalus" ${ }^{48}$ y sobre el mismo se disponía una cornisa con rica decoración. Bajo este un tapiz, en oro, azul y rojo, enmarcaba dieciséis grandes espejos (de 1 metro de ancho por 3 de alto) que ampliaban su interior. También bellos zócalos con azulejos dorados y de colores intensos (fabricados en La Cartuja de Sevilla) cubrían la parte inferior de sus paredes. El techo era plano, con iluminación cenital, y de él pendían cuatro lámparas, de inspiración arabizante. El mobiliario, como era habitual en estos establecimientos, estaba compuesto por cómodos divanes con respaldo, guarnecidos con terciopelo de color oliváceo, y mesas rectangulares de mármol con sillas de madera (distribuidas a través de la firma José Trobat y compañía, digna competidora valenciana de la reputada casa Thonet de Viena).

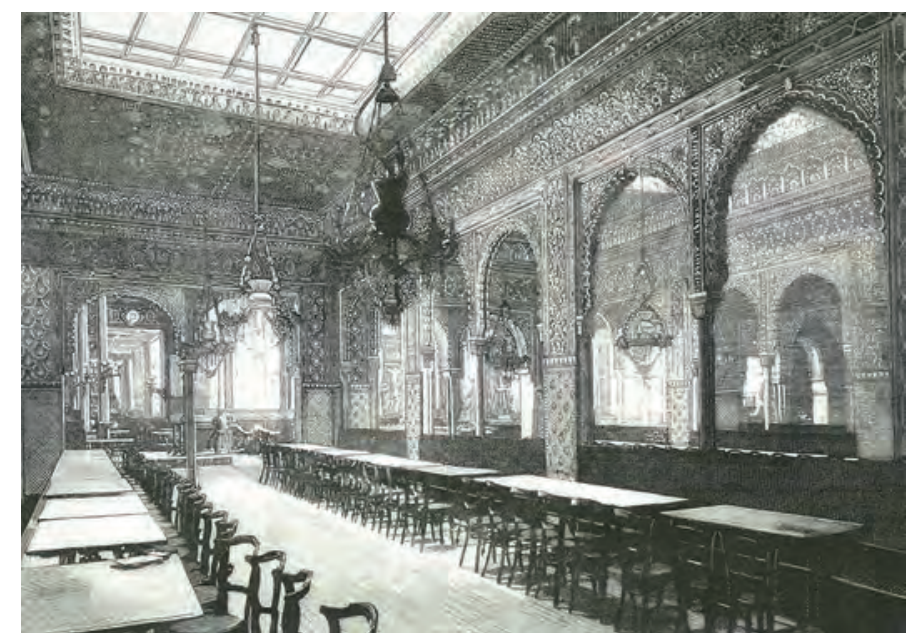

Fig. 5. Aspecto del salón árabe del café de España, 1889 ( $L a$ Ilustración española y americana, 22-III-1889). Biblioteca de la Diputación Provincial de Zaragoza.

Este espacio denominado "salón árabe" era famoso por las tertulias que en él se congregaban y que impulsaron el desarrollo cultural en esta ciudad. Uno de sus asiduos clientes fue el escritor José Martínez Ruiz (a quien se le conoce por el pseudónimo de Azorín, nombre que toma a uno de sus protagonistas) durante su residencia en Valencia entre el otoño de 1888 y el otoño de 1896, momento en el que se traslada definitivamente a Madrid. En su libro de recuerdos titulado Valencia, redactado durante los meses de febrero y marzo de 1940, se refiere a este café con estas emocionantes palabras:

Íbamos, tras la comida, al café de España. No lo había más suntuoso en Valencia. No lo habría tampoco en el mismo París [...]. Traspuesto un zaguán losado de mármol blanco, se entraba en un primoroso salón árabe, con frisos de alicatados azulejos. No era aquello una teatral imitación, sino una obra auténtica. Y de allí se pasaba a una vastísima sala decorada por los más ilustres pintores valencianos. En un extremo, sobre estrado, se veía un magnífico piano Errad. ${ }^{49}$

\footnotetext{
44 Este café fue nuevamente reformado, a principios del año 1923, por su propietario Rufino García. Las dos casas traseras de la calle de Moratín fueron derribadas, y en ese terreno se levantó un amplio salón ( 36 × $11 \mathrm{~m}$ ), que fue lujosamente decorado en estilo Renacimiento bajo la dirección del ebanista Carlos Cortina Beltrán (Tavernes Blanques, 1875-Valencia, 1949). Su inauguración se verificó el 3 de marzo de 1923. Diario de Valencia, 4-III-1923, "El café más bello de España", p. 2. Carlos Cortina fue un notable artista de trabajos en madera y de carrozas, decoraciones de calles y de fallas. Las Provincias. Diario de Valencia, 26-XII-1901, "Exposición artística del Círculo de Bellas Artes", p. 2; La Correspondencia de Valencia, 2-VIII-1904, "Noticias locales", p. 2.

45 El Mercantil Valenciano, 5-II-1886, "El nuevo café de España", p. 2; ARAZO BALLESTER, Ma. Ángeles, 2014, p. 36.

${ }^{46}$ Este café estaba muy bien iluminado, dado que se colocaron 112 lámparas incandescentes, más otras 32 en el salón árabe y 16 en la fonda, sin contar las instaladas en las dependencias de la servidumbre. MARTíNEZ DE VELASCO, Eusebio, 1889, p. 171.

47 MARTíNEZ DE VELASCO, Eusebio, 1889, p. 171.

48 RIDAURA CUMPLIDO, Concha, 2018, p. 73-74.

${ }^{49}$ AZORÍN, 1995, p. 15.
} 
Asimismo, y a finales del siglo XIX, se celebraban en él exposiciones de arte como vehículo de promoción artística ${ }^{50}$ y actos culturales, con gran acogida por parte de los aficionados, como conciertos musicales dirigidos por el maestro Goñi. ${ }^{51}$ A principios de la siguiente centuria ofrecía conciertos los días laborables (a las nueve de la noche) en los meses de invierno a cargo del profesorado del Conservatorio municipal y por el distinguido artista Raimundo Calvo y el notable pianista José Bellver. ${ }^{52}$

Desde el "salón árabe" se entraba a un inmenso salón, de planta rectangular (15 metros de largo, 30 de ancho y 6 de altura), en el que se optó por un estilo artístico más contenido y refinado con motivos clasicistas (Fig. 6). Tenía techumbre artesonada con una amplia claraboya en el centro para proporcionarle luz y ventilación, que se apoyaba en cuatro finas columnas de hierro fundido y forma estriada, en cuyos capiteles se esculpieron los escudos de armas de las provincias españolas. En el techo, dividido en catorce rectángulos, se mostraron, en lienzos encerrados en tondos, alegorías representadas por matronas que personificaban la Marina, la Independencia, la Música, la Agricultura, la Industria, las Ciencias exactas, la Historia, el Comercio, la Jurisprudencia, la Literatura, la Escultura, la Arquitectura, la Pintura y la Poesía, ${ }^{53}$ debidas al pincel del acreditado artista Antonio Cortina Farinós. Formaban un conjunto admirable por el colorido, el dibujo y los efectos de luz. Bajo la claraboya, ocupando el centro del salón, se dispuso una escultura de la Fama (de 3 metros de altura, caracterizada como una figura femenina desnuda y alada que sostenía con su mano izquierda una trompeta y con la derecha un ramo de laurel), la cual descansaba sobre una esfera con cuatro relojes. Fue realizada por el escultor José Aixa Íñigo (Valencia, 1844-1920), uno de los principales protagonistas de la escultura monumental en la Valencia de finales del siglo XIX. ${ }^{54}$ La esfera estaba sustentada por un grupo de leones, a manera de pedestal, que fue ejecutado por el escultor José Viciano Martí (Castellón, 1855-1898). ${ }^{55}$ Entre las ocho columnas se colocaban mesas de mármol con sus sillas de madera, así como divanes junto a las paredes recubiertas con doce grandes espejos. Este diáfano y lujoso salón se iluminaba con veinte lámparas, con cinco luces cada una.

Asimismo, en el friso en el cual descansaba la claraboya se labraron escudos, así como medallones sobre los vanos adintelados y espejos que contenían bustos, en bajo relieve, de insignes escritores y artistas: Pedro Calderón de la Barca y Eduardo Rosales como representantes de la literatura y del arte madrileños; José Ribera y Juan de Juanes de la tierra valenciana; Jaume Balmes y Mariano Fortuny como maestros catalanes; y Diego Velázquez y Bartolomé Esteban Murillo como embajadores de Sevilla.

Por su parte, entre los espejos de las paredes (de 3,76 metros de alto) se distribuían cartelas en las cuales aparecían medallones de los "personajes más destacados de la patria", que se acompañaban de paneles (de 1 metro de ancho por 2 de alto) donde se pintaron en negro, para asemejar dibujos, episodios heroicos y significativos de su vida: Don Juan de Austria con un soldado del siglo XVI y un marino de Lepanto, obra de Carlos Giner; los Reyes Católi-

\footnotetext{
50 Luisa Sempere constata que en un departamento contiguo al salón principal del café de España, y situado en el paso hacia uno de los billares, se instaló una efímera exposición permanente de pinturas durante los primeros días que siguieron a la apertura de este establecimiento. Este espacio debió de desaparecer al comenzar las obras de la fonda, que se abrió el último día del mes de mayo de 1887. Esta iniciativa fue muy bien acogida por los artistas valencianos porque era un medio para dar a conocer de forma continuada sus obras. Presentaron trabajos artistas como José Vilar, Javier Juste, Enrique Valls, Vicente Nicolau Cotanda, José Benavent, Enrique Blay, Antonio Gomar y Emilio Sala. Junto a las pinturas se exhibieron tres terracotas de José Aixa. SEMPERE VILAPLANA, Luisa, 2004, p. 177-179.

51 Las Provincias. Diario de Valencia, 10-I-1898, "Valencia", p. 2.

52 José Bellver fue uno de los fundadores del Conservatorio de Música de Valencia. El Pueblo. Diario republicano de Valencia, 30-X-1910, "Noticias", p. 2.

${ }^{53}$ Estas escenas relacionadas con el progreso, las artes y las ciencias se realizaron atendiendo al gusto artístico imperante en esta época por las escenas alegóricas y mitológicas. En este período se abandonaron las representaciones religiosas y de temática histórica que caracterizaron los dos siglos anteriores. ALBA PAGÁN, Ester, 2001, p. 775.

${ }^{54}$ Este escultor realizó también, entre otras obras, la estatua de Esculapio y los relieves de la fachada de la antigua Facultad de Medicina (terminada de construir en 1883) y el decorado de la cervecería-restaurant El León de Oro (Lion d'Or) (plaza de Mariano Benlliure, junto al café de España). CISNEROS ÁLVAREZ, Pablo; NAVARRO CATALÁN, David Miguel, 2004, p. 112-113. Asimismo, en 1889, Ignacio Pinazo ejecutó un conjunto de pinturas para la cervecería-restaurant El León de Oro (propiedad de la familia Pampló, que fue inaugurada el 20 de diciembre de 1889). Su salón fue decorado con estos cuatro lienzos apaisados: Carnaval en la Alameda, Conversación en la «serre», Bella herida por Cupido y El cuento de las cabritas. Estas composiciones se conservan en el Museo Nacional de Cerámica y Artes Suntuarias González Martí de Valencia. PÉREZ ROJAS, Francisco Javier; ALCAIDE DELGADO, José Luis, 2011, p. 22-25 y 76-81.

55 MARTÍNEZ DE VELASCO, Eusebio, 1889, p. 171.
} 
cos y el sultán del reino nazarí Boabdil, junto con un paje, de Enrique Blay; una figura legendaria de la Reconquista, Rodrigo Díaz de Vivar, de Antonio Cortina;; ${ }^{56}$ Don Jaime I de Aragón el Conquistador -que fue rey de Valencia-, de Ignacio Pinazo; Don Alfonso VIII de Castilla, llamado el de las Navas, junto con un soldado, de José Aixa; los héroes del Dos de Mayo (Daoíz y Velarde), de José Benavent; y D. Leopoldo O'Donnell y la guerra de África (18591860), de Ricardo Franch.

Además, y como advierte Luisa Sempere, la destrucción de Numancia estaba figurada por la representación de una medalla de la época, obra de Mariano García. Seguía a esta un medallón con un busto tomado de una medalla saguntina, acompañado de dos alegorías realizadas por Enrique Valls. Frente al rey Jaime I, ocupaba un lugar de preferencia la efigie de Cervantes, quien tenía a sus lados los dos principales personajes de su famosa novela, Don Quijote y Sancho, cuyos dibujos se debieron a José Brel. Tras este intervalo literario, aparecían los soldados de los tercios de Flandes, pintados por Juan Peyró. A derecha e izquierda del último medallón con la imagen de Carlos $\mathrm{V}$ se encontraban el prisionero de Pavía y el Mellado, de Germán Gómez Nyederleytner. Por último, había unos aragoneses en conmemoración del Sitio de Zaragoza, obra ejecutada por el escultor Luis Gilabert. ${ }^{57}$

Como puede comprobarse, la mayoría de los temas representados corresponden a personas y asuntos históricos relevantes de la Edad Media y del primer Renacimiento (principalmente relacionados con el proceso denominado de la "Reconquista"). Por tanto, estas obras, como reflejo del panorama político del momento (con la reavivación de los regionalis-

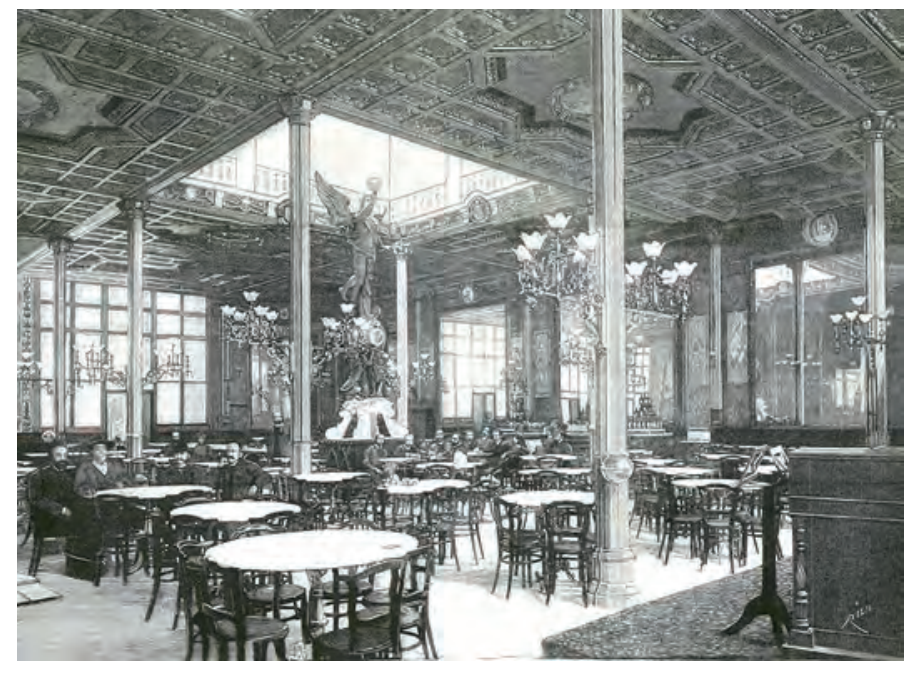

Fig. 6. Gran Salón o salón principal del café de España, 1889 (La Ilustración española y americana, 22-III-1889). Biblioteca de la Diputación Provincial de Zaragoza.

mos y nacionalismos), ${ }^{58}$ tienen un contenido simbólico puesto que pretendían recordar hechos pretéritos y rendir homenaje a personajes que intervinieron en la defensa de la "unidad nacional" y, en definitiva, de la idea de Hispanidad.

Estas obras citadas fueron ejecutadas, bajo la dirección decorativa del pintor Antonio Cortina Farinós (Almàssera, Valencia, 1841-Madrid, 1890), ${ }^{59}$ íntimo amigo de Carmelo Lacal, ${ }^{60}$ por prestigiosos artistas valencianos especializados en temas históricos como los pintores Ignacio Pinazo Camarlench (Valencia, 1849-Godella, 1916) ${ }^{61}$ y Carlos Giner Vidal (Va-

\footnotetext{
${ }^{56}$ Antonio Cortina pintó en esta escena al Cid y la afrenta a sus hijas perpetrada por los condes de Carrión; tema que le sedujo por los desnudos femeninos tan alabados por los críticos (de cuyos bocetos se conservan fragmentos en el Museo Nacional de Cerámica y Artes Suntuarias González Martí). ARAZO BALLESTER, Ma . Ángeles, 2014, p. 36.

57 SEMPERE VILAPLANA, Luisa, 2004, p. 176.

${ }^{58}$ FORCADELL ÁLVAREZ, Carlos; PEIRÓ MARTíN, Ignacio (coords.), 2002.

${ }^{59}$ Este pintor destacó en las temáticas religiosa e histórica y, en sus últimos años, realizó también esculturas en yeso y en barro. BOIX, Vicente, 1877, p. 24-25. Antonio Cortina fue comendador de la Real Orden de Isabel la Católica, profesor ayudante numerario en la Escuela de Bellas Artes de San Carlos de Valencia y socio honorario del Ateneo Científico, Literario y Artístico de esta ciudad. El 8 de junio de 1897 se verificó la traslación de sus restos mortales desde la estación del Norte de Madrid (ciudad en la que falleció) al cementerio de Valencia. El Regional, 8-VI-1897, "Noticias", p. 1; y El Regional, 9-VI-1897, "Entierro de los restos mortales de D. Antonio Cortina Farinós", p. 3.

60 José Antonio Sánchez Trigueros aporta un documento expedido y firmado por Carmelo Lacal Sorlí, el 14 de junio de 1890 en Valencia, en el que certifica que las obras de ornamentación del Gran Café de España se realizaron bajo la dirección del distinguido pintor Antonio Cortina Farinós. SÁNCHEZ TRIGUEROS, José Antonio, 2000, p. 249.

${ }^{61}$ Manuel González Martí señala que "el arte de Pinazo sobresale por su originalidad de psicólogo y colorista, que mira el natural y sabe interpretarlo fiel y honradamente, avalorándolo con una exquisitez y delicadeza de ejecución tan exenta de afectadas elegancias aprendidas, como llena de geniales habilidades". Dentro de la pintura decorativa, cabe decir que acometió la ornamentación de los techos del comedor y del salón de la casa de Esteban Martínez en la plaza de Mariano Benlliure, del techo del salón de la casa de Isabel Orellana o de los techos del palacio de Fontanals. GONZÁLEZ MARTí, Manuel, 1971،
} 
lencia, 1834-1917), ${ }^{62}$ entre otros; y por los escultores José Aixa Íñigo ${ }^{63}$ y Luis Gilabert Ponce (Valencia, 1848-1930), ${ }^{64}$ así como por otros no menos distinguidos en la vida artística valenciana del último tercio del siglo XIX y del primero de la siguiente centuria.

También participaron en la parte artística de este café José Puig y José Martí, que llevaron a cabo los trabajos de talla; Vicente Ríos, que se encargó de la fundición; y José Taboni, a quien correspondió la parte de pintura y decorado. ${ }^{65}$

La exuberancia del café de España respondió a la acertada dirección de Antonio Cortina, quien ya tenía una amplia experiencia en el campo de la pintura decorativa. Así, entre sus trabajos para locales de ocio y entretenimiento, sobresalen las pinturas del salón oriental del desaparecido café de París (calle de la Paz, junto a la plaza de la Reina, que se hallaba a unos pasos del café de España), que fue decorado para acoger con más complacencia a la burguesía valenciana. ${ }^{66}$ Este establecimiento público (con planta baja, entresuelo y dos en alzada) abrió sus puertas el 11 de diciembre de 1880 y cinco años después fue ampliado con un nuevo salón dividido en dos departamentos: uno, de estilo oriental, con referencia a motivos persas y egipcios; $y$, el segundo, al mundo japonés. Cortina pintó para el primero citado cuatro magníficos cuadros al óleo: ${ }^{67}$ una habanera dormitando en vaporosa hamaca, una valenciana, una gitana y una damisela parisién, así como bellas figuras femeninas que representaban alegóricamente el Café, la Horchata, el vino Manzanilla y el Champagne (en estos momentos bebidas de prestigio, de signo social elevado, que acabaron por difundirse y popularizarse), recurriendo así a una temática constante en la pin- tura decorativa de la época. Además, este artista ejecutó murales al fresco en edificios religiosos y civiles (como los del salón de la casa de la viuda del mariscal de campo Máximo Chulvi y Lledó) y decorados teatrales de variados argumentos. ${ }^{68}$

El café de España, tal como había anunciado la prensa valenciana con motivo de su apertura, era una "verdadera obra de arte" realizada por inspirados artistas. A este respecto, es interesante mencionar que otros cafés de otras partes de nuestra geografía ya habían recibido este mismo elogio, como fue el caso del madrileño café de Fornos (calle de Alcalá esquina con la de la Virgen de los Peligros), inaugurado el 20 de julio de 1870. El techo de su salón principal fue pintado con cuatro magníficos frescos por el malagueño José Vallejo y Galeazo, que representaban alegóricamente estas bebidas: el Té, el Café, el Chocolate y el Vino. En septiembre de 1879 fue reformado bajo la dirección de los artistas Ramón Guerrero -padre de la admirada actriz-y Emilio Sala Francés, quien decoró el techo con cuatro lienzos que plasmaban alegorías, de inspiración greco-romana, alusivas al fin del establecimiento (un Clásico puchero, el Café, el Té y el Vino). Tras esta obra acometida con arte y elegancia, la prensa madrileña comentó de él que "era un museo con las reputadas firmas de Sala, Vallejo, Gomar, Araujo, Perea, Guerrero y de otros artistas que compitieron en dar a los adornos un sello de buen gusto que armonizaba las diversas artes". ${ }^{69}$

\section{La etapa final del café de España}

La Fonda y el café de España continuaron su exitosa andadura aunque, a partir de finales del siglo XIX, se vieron afectados por el proceso de transformación de Valencia en una urbe moderna. ${ }^{70}$

p. 78 y p. 161-164. En este contexto, es interesante mencionar que este artista fue premiado en varias Exposiciones Nacionales de Bellas Artes por sus cuadros de temas históricos. Así, en la exposición celebrada en mayo de 1881 fue reconocido con una medalla de segunda clase, en la sección de Pintura, por su cuadro Últimos momentos del rey Don Jaime el Conquistador en el acto de entregar su espada a su hijo Don Pedro (óleo sobre lienzo, 300 x $497 \mathrm{~cm}$, Museo Nacional del Prado, Madrid) (documento núm. 14, p. 209). Para el conocimiento de las últimas aportaciones sobre la vida y obra de este pintor se recomienda, entre otros estudios, la consulta de PÉREZ ROJAS, Francisco Javier; ALCAIDE DELGADO, José Luis, 2001; PONS MORENO, Aida, 2015.

62 Este distinguido artista fue nombrado director de la Escuela oficial de Arte e Industrias de Valencia en febrero de 1903. Las Provincias. Diario de Valencia, 2-Il-1903, "Valencia", p. 2.

63 Para el estudio de las obras escultóricas de carácter público de José Aixa, véase DE LAS HERAS ESTEBAN, Helena, 2003.

64 DE LAS HERAS ESTEBAN, Helena, 2006, p. 131-145.

65 SEMPERE VILAPLANA, Luisa, 2004, p. 177.

66 Para el estudio de la formación del grupo social de la burguesía valenciana y su modo de vida se recomienda la consulta de PONS, Anaclet; SERNA, Justo, 1992; RIDAURA CUMPLIDO, Concha, 2006.

67 PINEDO HERRERO, Carmen; MAS ZURITA, Elvira, 2007, p. 89-90.

68 MAS ZURITA, Elvira, 2014, p. 15; PINEDO HERRERO, Carmen; MAS ZURITA, Elvira, 2007, p. 108-111. Los murales del techo (Alegoría de la Felicidad) de esta casa permanecen, en la actualidad, en la sede de la Uniò de Llauradors i Ramaders de Valencia.

69 VÁZQUEZ ASTORGA, Mónica, 2018, p. 15-19.

70 La extensión de la ciudad de Valencia tras el derribo de las murallas (iniciado en febrero de 1865) se realizó, a partir de 1884, mediante un Proyecto de ensanche elaborado por los arquitectos José Calvo Tomás, Luis Ferreres Soler y Joaquín María 
Los trabajos de urbanización conllevaron que en el fin de siglo comenzasen las obras del ensanche de la calle de San Vicente Mártir y que los señores Sánchez de León construyeran en esta vía, esquina con la plaza de la Reina, ${ }^{71}$ un edificio (1896), conforme a la dirección del arquitecto Lucas García Cardona. A este inmueble se trasladó el Gran Hotel, tras la supresión del Hotel y fonda de España -al no encontrar un nuevo inquilino cuando su arrendamiento llegaba a su fin-. El gerente de este último establecimiento, José Cazalbou, había decidido fundar otro que llenara las necesidades que quedaban sin satisfacer en este sector y, a este efecto, creó el elegante Gran Hotel, que fue inaugurado el 1 de junio de $1898 .^{72}$

Poco tiempo después, el 1 de diciembre de 1899, se verificó la apertura del Hotel Universal por Matías García, en un edificio recientemente erigido por el maestro de obras Vicente Alcayne Armengol, en la calle de las Barcas esquina con la plaza de San Francisco (actualmente plaza del Ayuntamiento), es decir, en un punto estratégico a nivel urbano..$^{73}$ En octubre de 1902, este establecimiento fue denominado Gran Hotel y fonda de España. ${ }^{74}$

El 18 de septiembre de 1902 se produjo la reapertura del antiguo hotel de la Bajada de San Francisco, núms. 7-9, con el título de Hotel Continental y bajo la dirección de J. Adolfo Jaubert. ${ }^{75}$ En mayo de 1903, los acreditados industriales Ángel Vicente (antiguo dueño del Hotel de Londres, calle Pascual y Genís, núm. 7) y José Souto (gerente que fue del Hotel de Londres) asumieron la gestión de este hotel (Ilamado Gran Hotel Continental) que estaba instalado en el edificio de la que fue Fonda de España, ${ }^{76}$ encima del café de España. En octubre de 1911, Rafael Narbón (quien estaba al frente del café de España, Bajada de San Francisco, núms. 7-9) se hizo cargo de este establecimiento, emprendió obras de reforma ${ }^{77}$ y cambió su nombre por el de Gran Hotel Colón.

La década de los veinte se inauguró con intensos conflictos sociales, una aguda lucha de clases y con huelgas y altercados. La relación entre patronos y obreros se recrudeció en 1920 y esta situación tuvo sus repercusiones en los cafés de la ciudad, que fueron escenario de agitados sucesos como de la explosión de una bomba en el interior de los cafés Suizo y de España, los días 24 y 28 de mayo de ese año, respectivamente. ${ }^{78}$

Después de un período de incidentes graves y de desórdenes sociales y políticos, Valencia fue saliendo de la incertidumbre en la que había estado sumida y reanudó su actividad urbana. De este modo, a la construcción de edificios públicos como el Ayuntamiento ${ }^{79}$ y la Casa de Correos y Telé-

Arnau Miramón. Se crearon nuevas calles, con importantes edificios, de acuerdo con las alineaciones diseñadas en él. Una importante obra que contará con dos importantes "grandes vías", que caracterizaron la expansión decimonónica. TABERNER

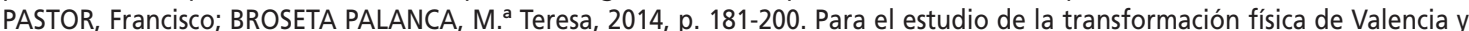
de sus planes de ensanche proyectados entre 1777 y 1912, véase, entre otras publicaciones, BENITO GOERLICH, Daniel, 1992, p. 1-17.

71 La plaza de la Reina fue definida por el arquitecto municipal Federico Aymamí (autor de un anteproyecto para la reforma interior de la ciudad en 1907) como "punto culminante del centro del lujo", de donde irradian, entre otras, las concurridas calles de San Vicente Mártir -eje tradicional de la ciudad que registró un asentamiento comercial de importancia- y de Peris y Valero (actual calle de la Paz). AYMAMí, Federico, 1908, p. 236

72 Las Provincias. Diario de Valencia, 1-VI-1898, "El Gran Hotel", p. 2; Las Provincias. Diario de Valencia, 2-VI-1898, "Valencia", p. 2; y Las Provincias. Diario de Valencia, 18-VI-1898, "Grand Hotel", p. 2.

73 Las Provincias. Diario de Valencia, 2-XII-1899, "Apertura de una fonda", p. 2.

74 En octubre de 1902 (tras la reapertura de la antigua Fonda de España y para distinguirse de la misma) este establecimiento pasó a denominarse Gran Hotel y fonda de España (calle del Pintor Sorolla, núms. 1-7, esquina con la plaza de Emilio Castelar -antes plaza de San Francisco-, núm. 12). El Pueblo. Diario republicano de Valencia, 22-X-1902, "Grand Hotel de España", p. 3.

75 Las Provincias. Diario de Valencia, 19-IX-1902, "Un nuevo hotel", p. 2. En noviembre de 1902 se declaró en estado de quiebra a J. Adolfo Jaubert, dueño de este hotel situado en la Bajada de San Francisco. Las Provincias. Diario de Valencia, 8-XI1902, "Edicto", p. 2.

76 La Correspondencia de Valencia, 19-V-1903, "Noticias locales", p. 2.

77 La Correspondencia de Valencia, 16-X-1911, "No se cierra el Gran Hotel Continental", p. 2

78 La bomba que estalló en el café Suizo tuvo consecuencias graves, dado que resultaron heridos varios clientes y produjo destrozos de considerable importancia. Las Provincias. Diario de Valencia, 25-V-1920, "Estalla una bomba en el café Suizo", pp. 1-2. Sin embargo, la bomba que hizo explosión en el café de España (colocada en uno de los retretes de los billares) ocasionó daños materiales de escasa envergadura. Las Provincias. Diario de Valencia, 29-V-1920, "Los crímenes del terrorismo", p. 1-2.

79 En realidad, se erigió una nueva fachada principal conforme al proyecto redactado por los arquitectos municipales Carlos Carbonell y Francisco Mora y aprobado en 1904. Posteriormente, se acometieron obras de adaptación y de reforma interior en este antiguo edificio sede del Ayuntamiento. BENITO GOERLICH, Daniel, 1992, p. 158-161. 
grafos (1915-1922) ${ }^{80}$ en la plaza del Ayuntamiento siguió la ordenación urbanística de su contorno hasta darle su forma actual. Las reformas de este centro ciudadano emprendidas por el Ayuntamiento de Valencia, de acuerdo con el proyecto elaborado por el arquitecto Javier Goerlich en 1927, supusieron la modificación de los sectores occidental y septentrional, con la demolición de edificios y la desaparición o ampliación (como la primitiva Bajada de San Francisco) de calles. ${ }^{81}$ En 1931 quedó configurado este espacio urbano, en el que se erigieron nuevos inmuebles entre 1925 y 1936, con un marcado carácter representativo. ${ }^{82}$

Por tanto, la Bajada de San Francisco, una de las calles más clásicas y típicas de Valencia, fue objeto de un proyecto de ensanche iniciado en enero de 1929 que conllevó la expropiación de parcelas y el derribo de antiguos edificios (entre ellos, el del café de España) en donde durante varias décadas había radicado el comercio local. De sus escombros surgió una ancha y amplia avenida, ${ }^{83}$ y el solar en el que estuvieron emplazados la Fonda y el café de España se halla ocupado hoy por un inmueble (construido entre 1931 y 1932 por el arquitecto Adrián Llombart Alegret ${ }^{84}$ ) que acoge en su planta baja una oficina del Banco Bilbao Vizcaya Argentaria (plaza del Ayuntamiento, núm. 9). ${ }^{85}$

Del antiguo café de España no queda hoy más que un etéreo recuerdo y alguna "huella" que nos permite regresar a ese mundo de ensueño recreado en su interior y hacer volar la imaginación hacia ese pasado bajo la influencia de la Alhambra.

\section{Bibliografía general}

ALBA PAGÁN, ESTER. "La pintura y los pintores valencianos en las 'Casitas' del Real Sitio de San Lorenzo del Escorial: Mariano Salvador Maella, Benito Espinós, José López Enguídanos y Mariano Sánchez". En: CAMPOS Y FERNÁNDEZ DE SEVILLA, F. J. (coord.). EI Monasterio del Escorial y la pintura. Actas del Simposium. San Lorenzo del Escorial, 2001, p. 759-784.

ARIZA MUÑOZ, Carmen. "El Jardín Botánico, el Casino de la Reina y Vista Alegre: jardines madrileños que fueron del Real Patrimonio". Reales Sitios. Revista del Patrimonio Nacional, 1985, $\mathrm{n}^{\circ} 86$, p. 37-44.

ARIZA MUÑOZ, Carmen. "Los jardines madrileños en el siglo XIX". En: OTERO CARVAJAL, L. E.; BAHAMONDE MAGRO, Á. (ed. lit.). Madrid en la sociedad del siglo XIX, vol. 2. Madrid: Comunidad de Madrid. Consejería de Cultura, 1986, p. 519-537.

AYMAMÍ, Federico. "Reforma interior de Valencia. Memoria explicativa". Arquitectura y Construcción, agosto de 1908 , p. $234-238$.

AZORÍN. Valencia (Introducción, notas y bibliografía de Santiago Riopérez y Milá). Madrid: Biblioteca Nueva, 1995.

BACIGALUPE, Carlos. Cafés parlantes de Bilbao. Del romanticismo a la Belle Époque. Bilbao: Caffé Baqué, 1995.

BENITO GOERLICH, Daniel. La arquitectura del eclecticismo en Valencia. Vertientes de la arquitectura valenciana entre 1875 y 1925. $2^{\mathrm{a}}$ ed. Valencia: Ayuntamiento de Valencia, 1992.

BOHIGAS, Oriol. Arquitectura modernista. Barcelona: Lumen, 1968.

BOIX, Vicente. Noticia de los artistas valencianos del siglo XIX. Valencia: Imprenta de Manuel Alufre, 1877.

BONET CORREA, Antonio. Los cafés históricos. Madrid: Cátedra, 2012

BUENO FIDEL, M. ${ }^{a}$ José. Arquitectura y nacionalismo (pabellones españoles en las exposiciones universales del siglo XIX). Málaga: Universidad de Málaga. Colegio de Arquitectos, 1987.

${ }^{80}$ La primera resolución por parte del Jurado, encargado de informar respecto a los anteproyectos presentados para la construcción de un edificio destinado a Casa de Correos y Telégrafos, se emitió en noviembre de 1914. Fue construida por el arquitecto zaragozano Miguel Ángel Navarro (1883-1956). Arquitectura y Construcción, noviembre de 1914, "Crónica artística", p. 263; CABELLO LAPIEDRA, Luis $\mathrm{M}^{\mathrm{a}}$, 1919, p. 93; BENITO GOERLICH, Daniel, 1992, p. 224-225. Este profesional concurrió también, en febrero de 1917, al concurso de anteproyectos de la Casa de Correos y Telégrafos (paseo de la Independencia) de Zaragoza, aunque su propuesta no fue seleccionada en la fase final. El Jurado eligió el proyecto formulado por el arquitecto Antonio Rubio Marín y su inauguración tuvo lugar el 12 de octubre de 1926. Heraldo de Aragón, 13-IV-1917, "La Casa de Correos", p. 1; y Heraldo de Aragón, 13-X-1926, "Con asistencia del ministro de la Gobernación se inauguraron ayer los servicios de la nueva Casa de Correos", p. 1.

81 SERRA DESFILIS, Amadeo, 1990, p. 144-145; SERRA DESFILIS, Amadeo, 1996.

82 De este modo, se levantaron edificios de viviendas, la nueva sede social del Ateneo Mercantil y el cine Rialto (1935). En el concurso de anteproyectos para la construcción del Ateneo Mercantil (convocado en 1927) participaron 66 arquitectos y, entre ellos, el zaragozano Miguel Ángel Navarro. Boletín de la Sociedad Central de Arquitectos, 30-IV-1927, "El Concurso del Ateneo Mercantil de Valencia", p. 15; y Arquitectura, abril y mayo de 1928, "Ateneo Mercantil de Valencia. Concurso de anteproyectos", p. 107-135.

83 CELSO. "La Valencia que desaparece. Hablando con el decano de la Bajada de San Francisco". Las Provincias. Diario de Valencia, 27-XII-1928, p. 3

84 Adrián Llombart fue alumno de la Escuela provincial de Bellas Artes de Valencia, en el curso académico 1896-1897. Después, estudió arquitectura en la Escuela Superior de Barcelona, realizando los ejercicios finales de carrera en diciembre de 1906. En 1911, desempeñaba el cargo de arquitecto de Hacienda, en Valencia. En enero de 1931 fue nombrado jefe de administración de tercera clase del Ministerio de Hacienda. El Regional, 2-VI-1897, "Escuela provincial de Bellas Artes", p. 2; La Vanguardia, 2-XII-1906, p. 4; El pueblo de Alicante, 20-IV-1911, "Noticias", p. 3; y Ahora, 16-I-1931, "Información política. Decretos de Hacienda", p. 4

85 GONZÁLEZ MARTÍ, Manuel, 1971, p. 167. 
CABELLO LAPIEDRA, Luis Ma. "Los nuevos edificios para Correos y Telégrafos", Arquitectura y Construcción, 1919, p. 93.

CALVO SERRALLER, Francisco. La imagen romántica de España. Arte y arquitectura del siglo XIX. Madrid: Alianza Forma, 1995.

CAMPOS Y FERNÁNDEZ DE SEVILLA, Francisco Javier (coord.). El Monasterio del Escorial y la pintura, Actas del Simposium. San Lorenzo de El Escorial: Real Centro Universitario Escorial-María Cristina, 2001.

CISNEROS ÁLVAREZ, Pablo; NAVARRO CATALÁN, David Miguel. "José Aixa y la Real Academia de Bellas Artes de San Carlos de Valencia". Archivo de Arte Valenciano, 2004, LXXXV, p. 109-117.

CRUZ VALENCIANO, Jesús. El surgimiento de la cultura burguesa. Personas, hogares y ciudades en la España del siglo XIX. Madrid: Siglo XXI de España Editores, S.A., 2014.

CRUZ VALENCIANO, Jesús. "Espacios públicos y modernidad urbana: la historia de los jardines de recreo en la España del siglo XIX". Historia Social, 2015, n 83, p. 37-54.

DE LAS HERAS ESTEBAN, Helena. La escultura pública en Valencia. Estudio y catálogo. Valencia: Universitat de València. Servei de Publicacions, 2003. Tesis doctoral en línea disponible en http://hdl.handle.net/10803/ 9965.

DE LAS HERAS ESTEBAN, Helena. "En memoria del escultor valenciano Luis Gilabert Ponce (1848-1930)". Archivo de Arte Valenciano, 2006, LXXXVII, p. 131-145.

FORCADELL ÁlVAREZ, Carlos; PEIRÓ MARTíN, Ignacio (coords.). Lectura de la historia: nueve reflexiones sobre historia de la historiografía. Zaragoza: Institución Fernando el Católico, 2002.

FORTÚN SOFÍ, Ricardo (dir.). Guía de Zaragoza y de la región aragonesa: anuario para 1902. Zaragoza: Imprenta M. Ventura, 1901.

GIRONÉS SARRIÓ, Ignasi (coord.). La pintura a les col.leccions particulars d'Ontinyent i la Vall d'Albaida. Ontinyent: La Nostra Terra, 2013.

GONZÁLEZ MARTÍ, Manuel. Pintores valencianos del siglo XIX. Pinazo, su vida y su obra (1849 a 1916). $2^{\text {a }}$ edición. Valencia: Ayuntamiento de Valencia, 1971.

GUEREÑA, Jean-Louis. "Espacios y formas de sociabilidad en la España Contemporánea". Hispania, 2003, LXIII/2, n² 214, p. 409-414.

MARTÍNEZ DE VELASCO, Eusebio. "Valencia: El salón árabe y el salón principal del Café de España". La Ilustración española y americana, 22-III-1889, p. 171.

MAS ZURITA, Elvira (coord.). Redescubriendo al pintor Antonio Cortina 1841-1890. Valencia: Generalitat Valenciana. Consorci de Museus de la Comunitat Valenciana, 2014.

MÉNDEZ RODRÍGUEZ, Luis. La imagen de Andalucía en el arte del siglo XIX. Sevilla: Centro de Estudios Andaluces, 2008.

NAVASCUÉS PALACIO, Pedro. Arquitectura y arquitectos madrileños del siglo XIX. Madrid: Instituto de Estudios Madrileños, 1973.

NAVASCUÉS PALACIO, Pedro. Un palacio romántico. Madrid, 1846-1858. Madrid: Ediciones El Viso, S.A., 1983.

PASCUAL SANPONS, Oriol. Barcelona Orientalista. Barcelona: Albertí Editor, 2017.

PÉREZ ROJAS, Francisco Javier; ALCAIDE, José Luis. Ignacio Pinazo en la colección del IVAM (catálogo de la exposición). Valencia: Aldeasa-IVAM, 2001.
PÉREZ ROJAS, Francisco Javier; ALCAIDE DELGADO, José Luis. Ignacio Pinazo. Zaragoza: Aneto Publicaciones, S.L., 2011.

PINEDO HERRERO, Carmen; MAS ZURITA, Elvira. El profesor que trajo las gallinas a la escuela: Antonio Cortina Farinós (1841-1890). Valencia: Institució Alfons el Magnànim-Diputació de València, 2007.

PONS, Anaclet; SERNA, Justo. La ciudad extensa. La burguesía comercial-financiera y su dominación en la Valencia de mediados del siglo XIX. Valencia: Diputació de València. Centre d'Estudis d'Història Local, 1992.

PONS MORENO, Aida. Ignacio Pinazo y la acuarela de su tiempo en Valencia. Valencia: Universidad de Valencia, 2015. Tesis doctoral en línea disponible en http//hdl. handle.net/10550/49605.

PRIEGO, Carmen (ed.). Dibujos en el Museo de Historia de Madrid. Arquitectura madrileña de los siglos XIX y $X X$. Madrid: Ayuntamiento de Madrid. Museo de Historia de Madrid, 2009.

RAQUEJO, Tonia. El palacio encantado. La Alhambra en el arte británico. Madrid: Taurus Humanidades, 1989.

RIBAGORDA, Álvaro. Caminos de la modernidad. Espacios e instituciones culturales de la Edad de Plata (1898-1936). Madrid: Editorial Biblioteca Nueva, 2009.

RIDAURA CUMPLIDO, Concha. Vida cotidiana y confort en la Valencia burguesa (1850-1900). Valencia: Generalitat Valenciana, 2006.

RIDAURA CUMPLIDO, Concha. "Los cafés como espacios de sociabilidad, de recreo y de modernidad en la Valencia burguesa del siglo XIX". En: MARTí OLTRA, J. (com.). Ens fem un café? ¿Tomamos un café? València: Ajuntament de València, 2018, p. 45-84.

RODRÍGUEZ DOMINGO, José Manuel. "El medievalismo islámico en el pensamiento arquitectónico español durante el siglo XIX". En: ANTIGÜEDAD DEL CASTILLOOLIVARES, M. ${ }^{a}$ D.; CIRICI NARVÁEZ, J. R. (coord.). Arquitectura y ciudad en España de 1845 a 1898 (Actas de las I Jornadas de Arquitectura Histórica y Urbanismo). Cádiz: Servicio de Publicaciones de la Universidad de Cádiz y Departamento de Historia del Arte de la UNED, 2000, p. 43-56.

SÁNCHEZ TRIGUEROS, José Antonio. Documentos sobre pintores valencianos del siglo XIX, Tomo I. Valencia: Diputació de València. Institució Alfons el Magnànim, 2000.

SAZATORNIL RUIZ, Luis; MADRID ÁLVAREZ, Vidal de la (coords.). Imago Urbis. Las ciudades españolas vistas por los viajeros (siglos XVI-XIX). Gijón: Ediciones Trea. Museo de Bellas Artes de Asturias, 2019.

SEMPERE VILAPLANA, Luisa. "Los establecimientos hosteleros valencianos del siglo XIX como medio de proyección social del artista". En: BONET SOLVES, V. E. (com.). La aplicación del genio. La enseñanza en la Escuela de Bellas Artes de San Carlos y su proyección en la sociedad. Valencia: Generalitat Valenciana, 2004, p. 170-193.

SERRA DESFILIS, Amadeo. "Arquitectura y ciudad: el monumentalismo del nuevo centro urbano en la ciudad de Valencia (1926-1936)". Saitabi, 1990, n 40, p. 143155.

SERRA DESFILIS, Amadeo. Eclecticismo tardío y art déco en la ciudad de Valencia (1926-1936). Valencia: Ayuntamiento de Valencia, 1996.

SERRANO ESPINOSA, Francisco. Arquitectura y restauración arquitectónica en la Granada del siglo XIX: la familia Contreras. Tesis doctoral. Granada: Universidad de Granada, 2014. 
TABERNER PASTOR, Francisco; BROSETA PALANCA, $\mathrm{M}^{\mathrm{a}}$ Teresa. "Arquitectura y desarrollo urbano. Notas sobre el ensanche de Valencia". Archivo de Arte Valenciano, 2014, XCV, p. 181-200.

VÁZQUEZ ASTORGA, Mónica. "Los antiguos cafés de Zaragoza en el siglo XIX". Brocar, 2014, n 38, p. 211239.

VÁZQUEZ ASTORGA, Mónica. Cafés de Zaragoza. Su biografía, 1797-1939. Zaragoza: Institución Fernando el Católico, 2015.

VÁZQUEZ ASTORGA, Mónica. "La vida social y cultural en los cafés europeos en el último cuarto del siglo XIX". En: CHAVES MARTÍN, M. Á. (dir.). Comunicación y Ciudad. Madrid: Universidad Complutense de Madrid, 2015, p. 23-37.

VÁZQUEZ ASTORGA, Mónica. "El café de Fornos (18701909) de Madrid, epicentro social y cultural en la calle de Alcalá". Arte y Ciudad, 2018, n 14, p. 7-32.

VÁZQUEZ ASTORGA, Mónica. "Estampa del Madrid antiguo: el café Suizo (1845-1919)". Ars Bilduma, 2019, no 9, p. 95-112.

VILLAR, Paco. Barcelona, ciudad de cafés (1880-1936). Barcelona: Ajuntament de Barcelona y Ediciones Invisibles, 2013.

\section{Prensa}

CELSO. "La Valencia que desaparece. Hablando con el decano de la Bajada de San Francisco". Las Provincias. Diario de Valencia, 27-XII-1928, p. 3.

Diario de Valencia, 4-III-1923, "El café más bello de España", p. 2.

Diario oficial de avisos de Madrid, 6-X-1861, "Variedades", p. 4

Diario oficial de avisos de Madrid, 12-X-1861, "Variedades", p. 4

El Día, 12-XI-1888, "Noticias varias", p. 3.

El Mercantil Valenciano, 5-II-1886, "El nuevo café de España", p. 2.
El Pueblo. Diario republicano de Valencia, 22-X-1902, "Grand Hotel de España", p. 3.

El Pueblo. Diario republicano de Valencia, 30-X-1910, "Noticias", p. 2.

El Regional, 8-VI-1897, "Noticias", p. 1.

El Regional, 9-VI-1897, "Entierro de los restos mortales de D. Antonio Cortina Farinós", p. 3.

Heraldo de Aragón, 21-VII-1900, "Noticias", p. 2.

Heraldo de Aragón, 13-IV-1917, "La Casa de Correos", p. 1.

Heraldo de Aragón, 13-X-1926, "Con asistencia del ministro de la Gobernación se inauguraron ayer los servicios de la nueva Casa de Correos", p. 1.

La Correspondencia de Valencia, 19-V-1903, "Noticias locales", p. 2.

La Correspondencia de Valencia, 16-X-1911, "No se cierra el Gran Hotel Continental", p. 2.

Las Provincias. Diario de Valencia, 2-VI-1887, "La nueva fonda de España", p. 2.

Las Provincias. Diario de Valencia, 10-I-1898, "Valencia", p. 2.

Las Provincias. Diario de Valencia, 1-VI-1898, "El Gran Hotel", p. 2.

Las Provincias. Diario de Valencia, 18-VI-1898, "Grand Hotel", p. 2.

Las Provincias. Diario de Valencia, 2-XII-1899, "Apertura de una fonda", p. 2.

Las Provincias. Diario de Valencia, 19-IX-1902, "Un nuevo hotel", p. 2.

Las Provincias. Diario de Valencia, 8-XI-1902, "Edicto", p. 2.

Las Provincias. Diario de Valencia, 2-II-1903, "Valencia", p. 2.

Las Provincias. Diario de Valencia, 25-V-1920, "Estalla una bomba en el café Suizo", p. 1-2.

Las Provincias. Diario de Valencia, 29-V-1920, "Los crímenes del terrorismo", p. 1-2. 